\author{
Marquette University \\ e-Publications@Marquette
}

College of Nursing Faculty Research and

Publications

Nursing, College of

2-1997

\title{
Adaptation of The Doubly Labeled Water Method for Subjects Consuming Isotopically Enriched Water
}

\author{
Randall J. Gretebeck \\ Marquette University, randall.gretebeck@marquette.edu \\ Dale A. Schoeller \\ University of Chicago \\ Rick A. Socki \\ Johnson Space Center \\ Janis Davis-Street \\ Johnson Space Center \\ Everett K. Gibson \\ Johnson Space Center
}

See next page for additional authors

Follow this and additional works at: https://epublications.marquette.edu/nursing_fac

Part of the Nursing Commons

\section{Recommended Citation}

Gretebeck, Randall J.; Schoeller, Dale A.; Socki, Rick A.; Davis-Street, Janis; Gibson, Everett K.; Schulz, Leslie O.; and Lane, Helen W., "Adaptation of The Doubly Labeled Water Method for Subjects Consuming Isotopically Enriched Water" (1997). College of Nursing Faculty Research and Publications. 876.

https://epublications.marquette.edu/nursing_fac/876 


\section{Authors}

Randall J. Gretebeck, Dale A. Schoeller, Rick A. Socki, Janis Davis-Street, Everett K. Gibson, Leslie O. Schulz, and Helen W. Lane 
Marquette University

e-Publications@Marquette

\section{Nursing Faculty Research and Publications/College of Nursing}

This paper is NOT THE PUBLISHED VERSION.

Access the published version via the link in the citation below.

Journal of Applied Physiology, Vol. 82, No. 2 (February 1997): 563-570. DOI. This article is ( American Physiological Society and permission has been granted for this version to appear in $\underline{\mathrm{e}}-$

Publications@Marquette. American Physiological Society does not grant permission for this article to be further copied/distributed or hosted elsewhere without express permission from American Physiological Society.

\section{Adaptation of The Doubly Labeled Water Method for Subjects Consuming Isotopically Enriched Water}

Randall J. Gretebeck

Nutritional Biochemistry, Space and Life Sciences Directorate, National Aeronautics and Space Administration/Johnson Space Center, Houston, Texas

Dale A. Schoeller

The Committee on Human Nutrition and Nutritional Biology, University of Chicago, Department of Medicine, Chicago, Illinois

Rick A. Socki

Stable Isotope Laboratories, Space and Life Sciences Directorate, National Aeronautics and Space Administration/Johnson Space Center, Houston, Texas

Janis Davis-Street

Nutritional Biochemistry, Space and Life Sciences Directorate, National Aeronautics and Space Administration/Johnson Space Center, Houston, Texas

Everett K. Gibson 
Stable Isotope Laboratories, Space and Life Sciences Directorate, National Aeronautics and Space Administration/Johnson Space Center, Houston, Texas

\section{Leslie O. Schulz}

Health Sciences, University of Wisconsin, Milwaukee, Wisconsin

Helen W. Lane

Nutritional Biochemistry, Space and Life Sciences Directorate, National Aeronautics and Space Administration/Johnson Space Center, Houston, Texas

\section{Abstract}

Gretebeck, Randall J., Dale A. Schoeller, Rick A. Socki, Janis Davis-Street, Everett K. Gibson, Leslie O. Schulz, and Helen W. Lane. Adaptation of the doubly labeled water method for subjects consuming isotopically enriched water. J. Appl. Physiol. 82(2): 563-570, 1997.-The use of doubly labeled water (DLW) to measure energy expenditure is subject to error if the background abundance of the oxygen and hydrogen isotope tracers changes during the test period. This study evaluated the accuracy and precision of different methods by which such background isotope changes can be corrected, including a modified method that allows prediction of the baseline that would be achieved if subjects were to consume water from a given source indefinitely. Subjects in this study were eight women (4 test subjects and 4 control subjects) who consumed for 28 days water enriched to resemble drinking water aboard the United States space shuttle. Test subjects and control subjects were given a DLW dose on days 1 and 15, respectively. The change to an enriched water source produced a bias in expenditure calculations that exceeded $2.9 \mathrm{MJ} /$ day (35\%), relative to calculations from intake-balance. The proposed correction based on the predicted final abundance of ${ }^{18} \mathrm{O}$ and deuterium after equilibration to the new water source eliminated this bias, as did the traditional use of a control group. This new modified correction method is advantageous under field conditions when subject numbers are limited.

The doubly labeled water (DLW) method is ideally suited for measuring total energy expenditure (TEE) under field conditions, i.e., when subjects cannot be confined to a laboratory. This method is based on the isotopic equilibration of water labeled with deuterium $\left({ }^{2} \mathrm{H}\right)$ and ${ }^{18} \mathrm{O}$ with body water and bicarbonate. After a loading dose of DLW is given, the ${ }^{2} \mathrm{H}$ is eliminated from the body as water, whereas the ${ }^{18} \mathrm{O}$ is eliminated from the body as water and $\mathrm{CO}_{2}$. The difference between the elimination rates of ${ }^{2} \mathrm{H}$ and ${ }^{18} \mathrm{O}$, therefore, is proportional to $\mathrm{CO}_{2}$ production $\left(\mathrm{V}^{\circ} \mathrm{CO}_{2}\right)$ and, hence, energy expenditure (18). This method is accurate to $1-2 \%$, with precision ranging from 3 to $8 \%$ depending on the isotope dose, duration of study, rate of energy expenditure, and related conditions $(10,15)$.

The use of DLW to measure energy expenditure in human subjects is complicated when those subjects consume water of different isotopic proportions shortly before or during the period of measurement. This change can result in changes in baseline isotope abundance and, therefore, can interfere with the accuracy of energy-expenditure measurements $(4,7)$. For example, energy expenditure by United States space shuttle astronauts is measured with DLW before and during flights, but these subjects consume water from at least three sources (Johnson Space Center in Houston, TX; Kennedy Space Center at Cape Canaveral, FL; and the space shuttle itself) shortly before or during energy-expenditure measurements. Of these, the potable water on the space shuttles is a particular isotopic problem, as it is produced by fuel cells during production of electrical power. Shuttle fuel cells convert gaseous 
hydrogen and oxygen to water, which is enriched $\mathrm{in}^{2} \mathrm{H}$ and ${ }^{18} \mathrm{O}$ in accordance with the isotopic enrichment of the gases. This enrichment, although not harmful to the crew, might affect both the accuracy and the precision of the DLW technique for measuring energy expenditure.

The simplest solution to the problem posed above would be to increase the dose of the isotope markers to the point at which errors in the natural background become negligible. Dose size influences accuracy and precision in two ways. First, a larger dose produces a larger signal relative to the random error in the isotopic measurement, improving the precision of the measurement. Second, a larger dose increases the signal relative to variations in the natural abundance of ${ }^{2} \mathrm{H}$ and ${ }^{18} \mathrm{O}$ in body water. These variations in natural abundance arise both from isotopic fractionation and from the isotopic constituents of the food, water, and air that enter the body $(2,3,21,22)$. However, this solution is impractical for two reasons, the first being the expense of ${ }^{18} \mathrm{O}$ and the second the complications associated with measuring high enrichments from such large doses accurately with current gas-inlet isotope-ratio mass spectrometers.

Another more practical alternative is to use control subjects who are not given DLW $(4,6,7)$ so that the background isotopic abundance of the two groups can be compared over time. This method has been used under conditions of moderate change in the isotopic abundance of drinking water but has never been rigorously validated (under controlled conditions) (4). Inclusion of control subjects in two studies $(4,7)$ maintained the accuracy of the DLW method, but the precision of the TEE measurements was $7 \%$ $(4,7)$. This approach is not ideal for space research, because the numbers of astronaut subjects available for study are limited. Moreover, the isotopic abundance in the water consumed during space shuttle flights tends to be greater than that reported in the studies described above $(4,7)$ and thus may degrade precision still further.

A third alternative has been to allow a period of equilibration (usually 1-3 wk) during which subjects consume water from the new source before the DLW dose is given (16). This approach, which also has been validated (16), preserves the accuracy and precision of TEE measurements, but the time required for equilibration may be a limiting factor, especially if the rate of water turnover is low or the difference between the initial and subsequent sources of drinking water is large. An equilibration period is particularly impractical for space crew members, because current space shuttle missions typically last only 7-13 days.

A fourth approach has been to predict the change in baseline as a function of time and the difference in isotopic abundances of the two water sources in question (8). These changes are added to (or subtracted from) the apparent enrichments of each postdose sample in a time point-by-time point basis to obtain the enrichment relative to the shifting baseline value. We recently realized that in the presence of a step change in the abundance of any of the inputs to the body it is possible to simplify this correction by only estimating the abundance of the baseline after the subject equilibrates to the new source of oxygen and hydrogen.

The purpose of this study was to investigate a new means of adjusting for shifts in isotope abundance, which is a modification of the method by Jones et al. (8) in that it does not require a time function. This method involves predicting the new baseline isotopic abundance, as though subjects had undergone a 
full period of equilibration to a new water source. We present the theoretical basis for this correction as well as validations and comparisons with other methods.

\section{METHODS}

\section{Subjects.}

Eight healthy women (Table 1), all residents of the metropolitan Houston, TX, area, were subjects in this 28-day ground-based study. All subjects were active, i.e., they normally engaged in 30 min or more of aerobic exercise at least three times weekly and continued to do so during the study. All subjects were pronounced healthy after a physical exam, and all were given the opportunity to sample the foods provided before signing an informed-consent statement to participate in the study. Seven of the subjects were allied health care professionals or nutrition/food scientists. After training in dietary record keeping, each subject interacted with a registered dietitian on a daily to weekly basis to verify completeness and accuracy of their logs. For the entire 28-day study, all subjects consumed only food items used on the space shuttle and tap water enriched with ${ }^{2} \mathrm{H}$ and ${ }^{18} \mathrm{O}$ to resemble the water available on a typical space shuttle mission.

Table 1. Subject characteristics

\begin{tabular}{|l|r|r|r|r|r|}
\hline Subject & \multicolumn{1}{|l|}{ Age, $\mathrm{yr}$} & \multicolumn{1}{l|}{ Height, cm } & Weight, $\mathrm{kg}$ & \%Fat & REE, MJ/day \\
\hline & & Test group & & & \\
\hline 1 & 45 & 160 & 56.6 & 26.1 & 4.56 \\
\hline 2 & 35 & 166 & 62.4 & 26.0 & 5.24 \\
\hline 3 & 45 & 165 & 62.4 & 27.0 & 5.76 \\
\hline 4 & 31 & 160 & 49.0 & 26.9 & 4.45 \\
\hline & & Control group & & & \\
\hline 5 & 47 & 171 & 58.6 & 17.7 & 6.27 \\
\hline 6 & 35 & 155 & 45.7 & 28.2 & 5.20 \\
\hline 7 & 33 & 168 & 55.4 & 21.8 & 6.24 \\
\hline 8 & 35 & 155 & 62.3 & 26.7 & 5.80 \\
\hline Mean \pm SD & $38.3 \pm 6.3$ & $163 \pm 5.9$ & $56.6 \pm 6.3$ & $25.1 \pm 3.5$ & $5.44 \pm 0.7$ \\
\hline
\end{tabular}

REE, postabsorptive resting energy expenditure.

The experimental design is illustrated in Fig.1. All subjects provided baseline urine and saliva samples at the Johnson Space Center Nutritional Biochemistry Laboratory after an overnight fast. Subjects were instructed to collect their first morning void for the next $4 \mathrm{wk}$. These urine samples were delivered daily to the laboratory for isotopic analysis as described below. Four of the eight subjects (the test group) were given DLW doses and began consuming enriched water on day 1 (i.e., no equilibration period). The remaining four (control) subjects also began consuming the enriched water onday 1 but were given their DLW doses on day 15. Additional urine and saliva samples were collected at the lab 5 $\mathrm{h}$ after the DLW dose. 


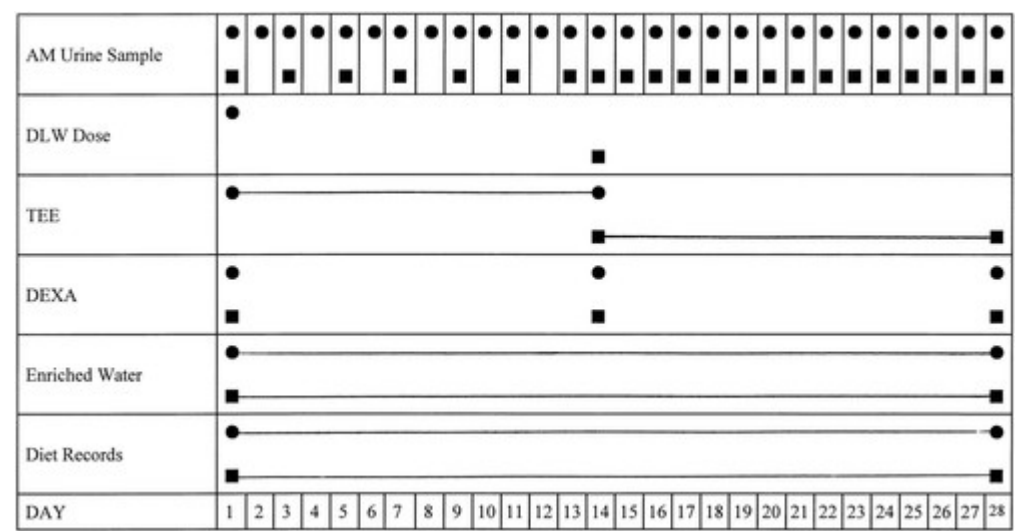

Fig. 1. Experimental design. Enriched water and shuttle foods were consumed, and urine samples were collected before noon (a.m.) throughout 28 -day period. Test subjects $(\bullet)$ received a doubly labeled water (DLW) dose onday 1 and control subjects (-) onday 15. Thus total energy expenditure (TEE) was determined during days 114 for test subjects and duringdays 15-28 for control subjects. Body composition was determined by dual energy X-ray absorptiometry (DEXA) at the beginning, middle, and end of study.

\section{Resting energy expenditure.}

Resting energy expenditure was measured ondays 1,15 , and 28 . Subjects arrived at the laboratory in the morning, after having fasted for at least the previous $8 \mathrm{~h}$ and rested supine in a darkened room for $20 \mathrm{~min}$ before the measurements were begun. Measurements were taken over 45-min periods by using a critical care monitor with a canopy system (Medical Graphics, St. Paul, MN) for breath-bybreath analysis of ${ }^{\prime} \mathrm{CO}_{2}$ and oxygen uptake $\left(\mathrm{V}^{\circ} \mathrm{O}_{2}\right)$. Subjects were instructed to rest quietly but remain awake during the measurements.

Diet.

Enriched water was made fresh every 3-4 days to minimize bacterial growth during storage by adding $8.75 \mathrm{ml}$ of $\mathrm{H}_{2}{ }^{18} \mathrm{O} 10$ atom percent excess (APE) and $0.25 \mathrm{ml}^{2} \mathrm{H}_{2} \mathrm{O}(99.8 \mathrm{APE})$ to 10 liters of Houston tap water. The isotopic abundance of randomly selected enriched water samples averaged $34.6 \pm 2.7 \%$ o for ${ }^{18} \mathrm{O}$ and $123 \pm 10 \%$ o for ${ }^{2} \mathrm{H}$. These concentrations were designed to represent the average isotope abundance in water samples retrieved after two space shuttle missions and were $34 \pm 2.8 \%$ o for ${ }^{18} \mathrm{O}$ and $125 \pm 70.7 \%$ o for ${ }^{2} \mathrm{H}$. The day-to-day SD within each mission averaged $0.7 \%$ o for ${ }^{18} \mathrm{O}$ and $2.8 \%$ o for ${ }^{2} \mathrm{H}$. The enriched water was carried by the subjects throughout the day and used to prepare drinks and rehydrate foods as well as for direct consumption.

All foods and fluids consumed throughout the study were weighed on calibrated electronic scales by the subjects and recorded in a standardized diary. All diets were self-selected from food items provided aboard the space shuttle vehicles. The majority of these food items were dehydrated, packaged individually, and reconstituted with enriched water. The use of a controlled inventory of supplied foods greatly enhanced the accuracy of food records that were reviewed weekly with a dietitian. All shuttle foods were analyzed for energy, fat, protein, and moisture content, with carbohydrate content calculated by difference.

Body composition.

Body composition was determined at the beginning, middle, and end of the study by dual-energy X-ray absorptiometry (Hologic model QDR 1000/W, Hologic, Waltham, MA). Whole body scans were 
obtained in the pencil-beam mode while the subjects rested supine, and scans were analyzed by using Hologic's whole body-analysis software (version 5.35). Body-composition results were reported as lean mass, bone mass, fat mass, and total mass. Percent body fat was calculated by dividing total fat mass by total body mass. The precision of the whole body scan within our laboratory was $0.87 \%$ for lean body mass and $1.71 \%$ for fat mass, respectively (20).

\section{DLW doses.}

Isotopes were purchased from Icon Services (Summit, NJ), and the doses were calculated as follows: 6.2 atom-percent $\mathrm{H}_{2}{ }^{18} \mathrm{O}$ mixed with 99.8 atom-percent ${ }^{2} \mathrm{H}_{2} \mathrm{O}$ to reach a 100-APE dose of $0.5 \mathrm{~g}$ of $\mathrm{H}_{2}{ }^{18} \mathrm{O}$ and $0.24 \mathrm{~g} \mathrm{of}^{2} \mathrm{H}_{2} \mathrm{O}$ per kilogram of lean body mass (estimated from body weight). DLW was administered in the morning after an overnight fast. Subjects continued their fast for an additional $5 \mathrm{~h}$.

Sample analyses.

Urine and saliva samples were centrifuged in the presence of activated charcoal, filtered, and stored frozen in cryogenically stable tubes at $-20^{\circ} \mathrm{C}$ until analysis by gas-inlet isotope-ratio mass spectrometry. Samples were analyzed for ${ }^{2} \mathrm{H}_{2} \mathrm{O}$ by zinc reduction at the University of Chicago, Department of Medicine (14), and for $\mathrm{H}_{2}{ }^{18} \mathrm{O}$ by $\mathrm{CO}_{2}$ equilibration at the Johnson Space Center, Stable Isotope Laboratory (19). Aliquots $(2 \mu \mathrm{l})$ were introduced into an evacuated side arm and allowed to distill over to a 6-mm OD quartz tube containing $40 \mathrm{mg}$ of zinc reagent (Biogeochemistry, Bloomington, IN) and were then cooled to liquid nitrogen temperatures. The tubes were sealed and heated to $500^{\circ} \mathrm{C}$ for $30 \mathrm{~min} .{ }^{2} \mathrm{H}$ analyses were performed in triplicate; SD values ranged from $1.5 \%$ for enrichments of $<200 \%$ o to $4.5 \%$ o for enrichments approaching 2,000\% when measured with a triple-inlet Nuclide 3-60 HD isotope ratio mass spectrometer (PATCO, Belefonte, PA).

The $\mathrm{CO}_{2}$ equilibration technique involved dispensing $1.5 \mathrm{ml}$ of sample into a 7-ml evacuated tube with $150 \mathrm{mmol}$ of $99.9 \%$ pure $\mathrm{CO}_{2}$. Samples were then shaken in a water bath at $25^{\circ} \mathrm{C}$ for at least $12 \mathrm{~h}$, and the $\mathrm{CO}_{2}$ was cryogenically removed and stored in 6- $\mathrm{mm}$ break-seal tubes. Samples were analyzed on a Finnigan MAT 251 stable-isotope mass spectrometer at Johnson Space Center. The reproducibility of this technique in this laboratory is $\pm 0.05 \%$ or better at the 1 SD confidence level (19).

Dilution spaces for $\mathrm{H}_{2}{ }^{18} \mathrm{O}$ and ${ }^{2} \mathrm{H}_{2} \mathrm{O}$ were calculated from the baseline and the 5 -h-after dose samples by using the equation

$$
N(\mathrm{~mol})=(W A / 18.02 a) /\left[\left(\delta_{a}-\delta_{t}\right) /\left(\delta_{s}-\delta_{p}\right)\right]
$$

Equation 1

where $\mathrm{N}$ is the pool space; $\mathrm{W}$ is the amount of water used to dilute the dose; $\mathrm{A}$ is the amount of dose administered; $a$ is the amount of dose diluted for analysis; and $\delta$ is the enrichment of the dose $\left(\delta_{a}\right)$, of the tap water $\left(\delta_{t}\right)$, of the 5 -h-after dose sample $\left(\delta_{s}\right)$, or of the baseline sample $\left(\delta_{p}\right)$.

$V^{\prime} \mathrm{CO}_{2}$ rate ( $\left.\mathrm{rCO} 2 \mathrm{rCO} 2\right)$ was calculated as described by Schoeller et al. (18) and Racette et al. (12) by using the equation

$$
r_{\mathrm{CO}_{2}}(\mathrm{~mol} / \mathrm{day})=(T B W / 2.078)\left(1.007 k_{O}-1.041 k_{H}\right)
$$




\section{Equation 2}

where TBW is the average total body water (calculated from $\mathrm{H}_{2}{ }^{18} \mathrm{O}$ and ${ }^{2} \mathrm{H}_{2} \mathrm{O}$ as shown in Eq. 1), $\mathrm{k}_{\mathrm{O}}$ and $\mathrm{k}_{\mathrm{H}}$ are the elimination rates of ${ }^{18} \mathrm{O}$ and ${ }^{2} \mathrm{H}$, respectively, and rate of water loss via fractionating gaseous routes $\left(\mathrm{r}_{\mathrm{Gf}}\right)$ is estimated as 1.05 TBW $\left(1.007 \mathrm{ko}_{\mathrm{O}}-1.041 \mathrm{k}_{\mathrm{H}}\right)$. (The isotope-elimination rates for these 8 subjects averaged $0.114 \pm 0.020 \mathrm{~mol} /$ day for ${ }^{18} \mathrm{O}$ and $0.092 \pm 0.018 \mathrm{~mol} /$ day for ${ }^{2} \mathrm{H}$.)

$\mathrm{V}^{\circ} \mathrm{O}_{2}$ was derived for each subject by dividing the $\mathrm{V}^{\cdot} \mathrm{CO}_{2}$ rate by the food quotient, which was derived from analysis of diet composition (1). TEE was calculated as described by de Weir (5).

Calculation of isotopic enrichment of body fluids. The appearance of ${ }^{2} \mathrm{H}$ and ${ }^{18} \mathrm{O}$ in body water after a step change in the enrichment of drinking water follows a single-exponential time course

$$
E=C_{t}-C_{\mathrm{bl}}=\left(C_{f}-C_{\mathrm{bl}}\right)\left(1-e^{-k t}\right)
$$

\section{Equation 3}

where $E$ is the isotopic enrichment relative to the baseline sample, $C$ is isotopic abundance, $k$ is the turnover rate of the element in body water, $t$ is time relative to the step change in abundance, and the subscriptst, bl, and f refer to the isotopic abundance at time $t$, at baseline $(t=0)$, and at final equilibration to the new water source. Figure 2illustrates theoretical changes in isotopic enrichment of body water.

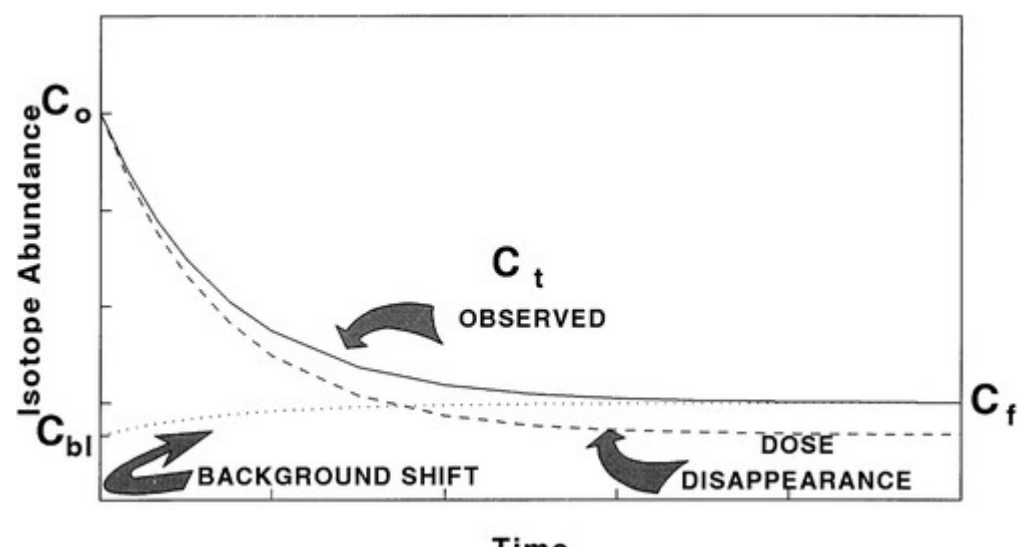

Fig. 2. Theoretical change in isotopic abundance in body water after a shift in enrichment of drinking water. $C_{0}$, original isotopic abundance after closing; $C_{b l}$, isotopic abundance at baseline; $C_{f}$, final isotopic abundance; $\mathrm{C}_{t}$ abundance attime $t$.

If a subject is given a dose of labeled water after having equilibrated to the new water source, then the elimination of the label is also described by a single-exponential function

$$
E=C_{t}-C_{\mathrm{bl}}=\left[C_{0}-C_{\mathrm{bl}}\right] e^{-k t}
$$

\section{Equation 4}

where the subscript 0 refers to the initial equilibrated isotopic abundance after the dose. 
In contrast, when the isotopic proportions of drinking water change at the same time as a dose of labeled water is given, the enrichment of body fluids will be the sum of both processes

$$
\begin{aligned}
E=C_{t}-C_{\mathrm{bl}} & =\left(C_{f}-C_{\mathrm{bl}}\right)\left(1-e^{-k t}\right)+\left(C_{0}-C_{\mathrm{bl}}\right) e^{-k t} \\
& =\left(C_{0}-C_{f}\right) e^{-k t}+\left(C_{f}-C_{\mathrm{bl}}\right)
\end{aligned}
$$

Equation 5

Taking the natural logarithm of both sides of Eq.5 and solving for $\mathrm{k}$ yields

$$
k=\Delta\left[\ln \left(C_{t}-C_{f}\right)\right] / \Delta t
$$

Equation 6

AsEq. 6 demonstrates, the only factors needed to calculate isotope-elimination rates are the isotopic abundances during the metabolic period and the final isotopic abundance after equilibration to the new water source.

Correcting for changes in drinking-water enrichment.

Because of the difficulty noted above in allowing time for complete equilibration to new water sources during space research, we used three methods to estimate what the ${ }^{2} \mathrm{H}$ and ${ }^{18} \mathrm{O}$ abundance would be in our subjects if they had equilibrated fully to the new drinking water (9-10 biological half-lives). The first method, isotopic mass balance, allowed final values for ${ }^{2} \mathrm{H}(E q .7)$ and ${ }^{18} \mathrm{O}$ (Eq. 8) to be predicted from the isotopic enrichment of the drinking water, food, and air $(14,17)$

$$
R_{\mathrm{bl}}=\left(X_{\mathrm{wH}} R_{\mathrm{wH}}+X_{f H} R_{\mathrm{fH}}\right) /\left(X_{\mathrm{nf}}+f_{1} X_{f}\right)
$$

\section{Equation 7}

where $R_{f b l}$ is the ratio of heavy-to-light hydrogen at the final equilibrated time (i.e., the new baseline); $\mathrm{R}$ is the ratio of heavy-to-light hydrogen (derived from the $\mathrm{d}$ values for ${ }^{2} \mathrm{H}$ in water and in food); $\mathrm{X}$ is the fraction of hydrogen influx from water $(w)$ or food $(f)$ or hydrogen efflux via nonfractionated water output (nf) or fractionated water output ( $f$ ); and

$$
\begin{aligned}
& R_{\mathrm{fbl}}=\left(\begin{array}{lllllll}
X_{\mathrm{wO}} & R_{\mathrm{wO}}+X_{f} o R_{f} o+f_{4} X_{o} R_{O_{2}}
\end{array}\right) / \\
& \left(X_{\mathrm{nf}}+f_{2} X_{f}+f_{3} X_{\mathrm{CO}_{2}}\right)
\end{aligned}
$$

\section{Equation 8}

where $R_{f b l}$ is the ratio of heavy-to-light oxygen (subscript $O$ ) at the final equilibrated time (i.e., the new baseline); $\mathrm{R}$ is the ratio of heavy-to-light oxygen (derived from the $\mathrm{d}$ values for ${ }^{18} \mathrm{O}$ in water and in food); $X$ is the fraction of oxygen influx or efflux (see Table 2); $f_{2}$ is the liquid-gas fractionation factor for oxygen in water; $f_{3}$ is the fractionation factor for oxygen in liquid water and $\mathrm{CO}_{2}$; and $\mathrm{f}_{4}$ is the fractionation factor forV $\mathrm{O}_{2}$ in the lung. The variables used in these calculations are listed in Table 2.

Table 2. Isotopic mass balance variables 


\begin{tabular}{|l|l|l|l|}
\hline Symbol & Definition & Value & Reference \\
\hline $\mathrm{X}_{\mathrm{wO}}$ & Fraction of O influx as water & 0.62 & Measured \\
\hline $\mathrm{X}_{\mathrm{fO}}$ & Fraction of O influx as food & 0.14 & Measured \\
\hline $\mathrm{X}_{\mathrm{O} 2}$ & Fraction of O influx as molecular $\mathrm{O}_{2}$ & 0.24 & Estimated from $\mathrm{EE}$ \\
\hline$\delta_{\mathrm{OW}}$ & ${ }^{18} \mathrm{O}$ abundance in water & 34.6 & Measured \\
\hline$\delta_{\mathrm{fO}}$ & ${ }^{18} \mathrm{O}$ abundance in food & 23 & $\mathbf{2 2}$ \\
\hline$\delta_{\mathrm{O} 2}$ & ${ }^{18}$ O abundance in molecular $\mathrm{O}_{2}$ & 23.5 & $\mathbf{2 2}$ \\
\hline $\mathrm{X}_{\mathrm{nf}}$ & Fraction of O efflux not fractionated water & 0.62 & Measured \\
\hline $\mathrm{X}_{\mathrm{f}}$ & Fraction of $\mathrm{O}$ efflux fractionated water & 0.14 & $\mathbf{1 7}$ \\
\hline $\mathrm{X}_{\mathrm{CO} 2}$ & Fraction of $\mathrm{O}$ efflux as $\mathrm{CO}_{2}$ & 0.24 & $\mathbf{1 7}$ \\
\hline $\mathrm{X}_{\mathrm{wH}}$ & Fraction of $\mathrm{H}$ influx as water & 0.81 & Measured \\
\hline $\mathrm{X}_{\mathrm{fH}}$ & Fraction of $\mathrm{H}$ influx as food & 0.19 & Measured \\
\hline$\delta_{\mathrm{wH}}$ & Deuterium abundance in water & 123 & Measured \\
\hline$\delta_{\mathrm{fH}}$ & Deuterium abundance in food & -65 & Measured \\
\hline $\mathrm{X}_{\mathrm{nf}}$ & Fraction of $\mathrm{H}$ efflux not fractionated water & 0.76 & Measured \\
\hline $\mathrm{X}_{\mathrm{f}}$ & Fraction of $\mathrm{H}$ efflux fractionated water & 0.24 & Measured \\
\hline $\mathrm{f}_{1}$ & ${ }^{2} \mathrm{H}$ fractionation from water vapor to water & 0.94 & $\mathbf{1 7}$ \\
\hline $\mathrm{f}_{2}$ & ${ }^{18} \mathrm{O}$ fractionation from water vapor to water & 0.992 & $\mathbf{1 7}$ \\
\hline $\mathrm{f}_{3}$ & ${ }^{18} \mathrm{O}$ fractionation from $\mathrm{CO}_{2}$ to water & 1.038 & $\mathbf{1 7}$ \\
\hline $\mathrm{f}_{4}$ & ${ }^{18} \mathrm{O}$ fractionation from $\mathrm{O}_{2}$ uptake & 0.992 & $\mathbf{2 2}$ \\
\hline
\end{tabular}

$\mathrm{EE}$, energy expenditure.

The second and third methods of estimating isotopic abundance after full equilibration involved fitting exponential models to the data. The model used for the second method, which focused on isotope elimination after a simultaneous change in drinking water and a DLW dose, was

$$
A_{t}=K(1) e^{-k t}+K(2)
$$

Equation 9

where $A_{t}$ is the amount of the tracer in the body at time $t \mathrm{~K}(1)=\mathrm{C}_{0}-\mathrm{C}_{f}$ and $\mathrm{K}(2)=\mathrm{C}_{f}-\mathrm{C}_{\mathrm{bl}}$. The CONSAAM program for PC (version 29; National Institutes of Health/National Cancer Institute, Bethesda, MD) was used to fit the model. The third method was to fit another exponential model to the isotopic abundance changes in control subjects who changed water sources but were not given the DLW dose until 15 days later. The control subjects did not receive DLW untilday 15, so the isotope appearance in these subjects could be used to correct for background changes in the test subjects who received DLW on day 1 . That model was

$$
C_{t}=K(3)\left[1-e^{-\mathrm{kt}}\right]+K(4)
$$

Equation 10

where $K(3)=C_{f}-C_{b l}$ and $K(4)=C_{b l}$.

Statistical analyses. Results are presented as means \pm SD. Energy expenditure calculations from the three enrichment adjustment methods were compared with calculations from the energy intake balance method by using pairedt-tests. Variances were compared by using F-tests. 


\section{RESULTS}

Samples of tap water collected at the Johnson Space Center were found to contain $-4.4 \%{ }^{18} \mathrm{O}$ and $-25.2 \%{ }^{2} \mathrm{H}$, relative to standard mean ocean water (smow). Urine samples collected before subjects began consuming the enriched water contained $0.49 \pm 1.6 \%{ }^{18} \mathrm{O}$ and $-12.65 \pm 6.3 \%{ }^{2} \mathrm{H}$ (means and SD values for 8 subjects).

The change in isotopic enrichment of body fluids for those subjects who consumed the enriched water for 2 wk before receiving the DLW dose (isotope appearance) is shown in Fig. 3. The equilibrated baseline abundance predicted from mass balance (Eqs. 7 and 8 ) for these subjects was $20.0 \%$ o for ${ }^{18} \mathrm{O}$ and $110.9 \%$ o for ${ }^{2} \mathrm{H}$.

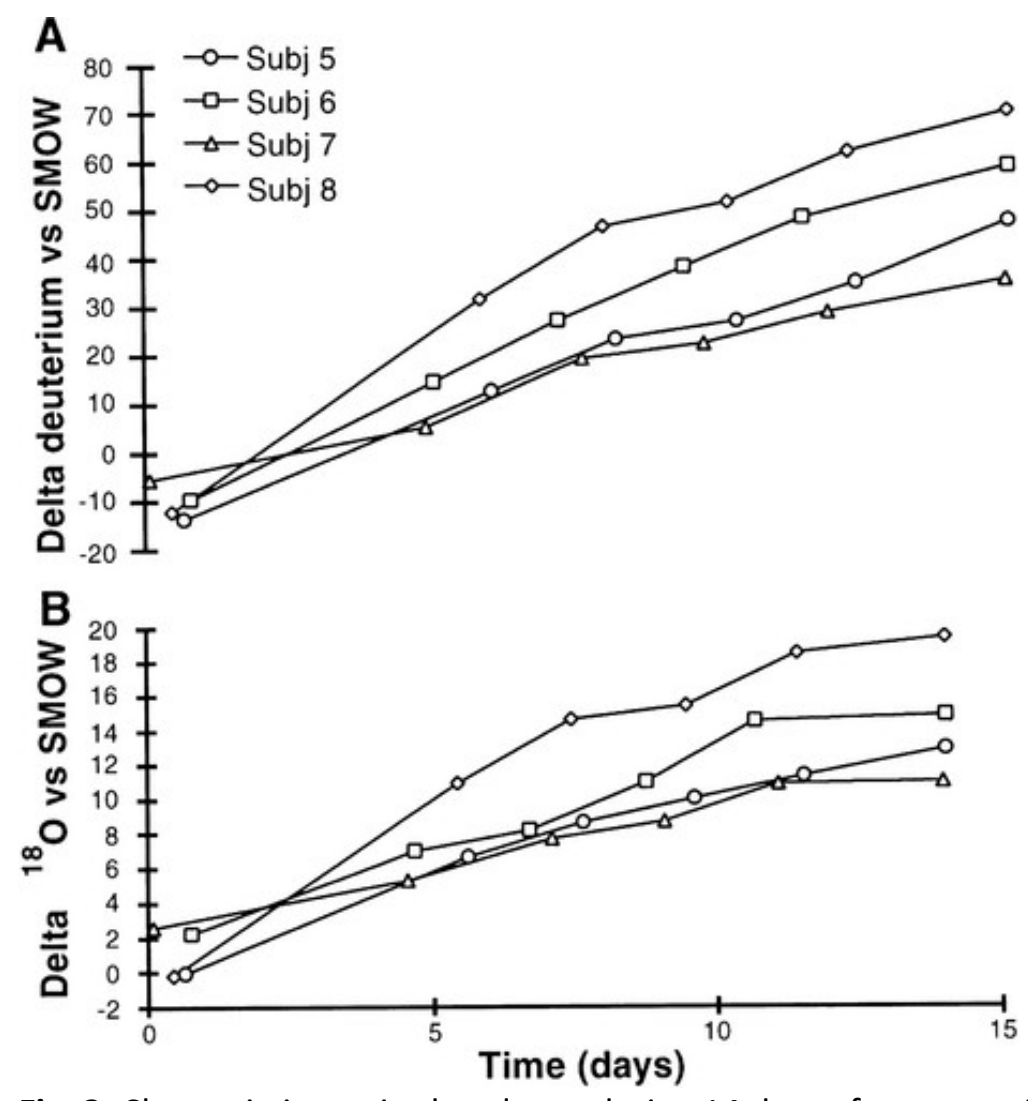

Fig. 3. Change in isotopic abundance during 14 days of consumption of water artificially enriched with ${ }^{2} \mathrm{H}$ and ${ }^{18} \mathrm{O}$ to mimic enrichment of potable water aboard United States space shuttle vehicles.A: deuterium isotope appearance $. B:^{18} \mathrm{O}$ isotope appearance.smow, standard mean ocean water; subj, subject.

Table 3 presents isotopic abundance values from urine samples collected before and after consumption of enriched water. Baseline isotopic abundance after equilibration to the enriched water was estimated from isotope-appearance (Eq.10) and -disappearance (Eq.9) kinetics. The value estimated from the appearance kinetics (Eq. 10, extrapolated to infinite time) (Table 3) was similar to that predicted from mass balance. The average values predicted from the disappearance kinetics (Eq. 9, extrapolated to infinite time) were not different; however, the individual values were unexpectedly variable (Table 3 ). 
Table 3. Isotope abundance in urine samples collected before and after a 2-wk equilibration to enriched water

\begin{tabular}{|c|c|c|c|c|c|c|c|c|}
\hline Subject & $\begin{array}{l}\text { Measured } \\
\text { on } \\
\text { StudyDay } 0\end{array}$ & & $\begin{array}{l}\text { Measured on } \\
\text { Study Day } 14\end{array}$ & & $\begin{array}{l}\text { Predicted From } \\
\text { Isotope Appearance } \\
\text { Kinetics (from Eq. 10) }\end{array}$ & & \begin{tabular}{|l|} 
Predicted From \\
Isotope \\
Disappearance \\
Kinetics \\
(from Eq. $\underline{\text { f) }}$ \\
\end{tabular} & \\
\hline & $\delta^{18} \mathrm{O}$ & $\delta^{2} \mathrm{H}$ & $\delta^{18} \mathrm{O}$ & $\delta^{2} \mathrm{H}$ & $\delta^{18} \mathrm{O}$ & $\delta^{2} \mathrm{H}$ & $\delta^{18} \mathrm{O}$ & $\delta^{2} \mathrm{H}$ \\
\hline & & & & & Test group & & & \\
\hline 1 & -2.1 & -16.8 & & & & & 27.7 & 131 \\
\hline 2 & 0.5 & -24.0 & & & & & 10.1 & -24 \\
\hline 3 & 1.8 & -4.3 & & & & & 36.2 & 263 \\
\hline 4 & -0.9 & -14.7 & & & & & 28.7 & 233 \\
\hline \multirow[t]{2}{*}{ Mean \pm SD } & $-0.2 \pm 1.7$ & $-14.9 \pm 8.1$ & & & & & $25.7 \pm 11.1$ & $150 \pm 129$ \\
\hline & & & & & Control group & & & \\
\hline 5 & -0.1 & -13.8 & 12.9 & 47.9 & 21.2 & 124 & 4.2 & -34 \\
\hline 6 & 2.2 & -9.7 & 14.9 & 59.3 & 18.5 & 75 & 25.3 & 373 \\
\hline 7 & 2.6 & -5.6 & 11.0 & 35.7 & 15.5 & 121 & -22.2 & 212 \\
\hline 8 & -0.2 & -12.3 & 19.1 & 72.2 & 24.9 & 114 & 44.8 & 52 \\
\hline Mean \pm SD & $1.1 \pm 1.5$ & $-10.4 \pm 3.6$ & $14.5 \pm 3.5$ & $53.8 \pm 15.6$ & $20.0 \pm 4.0$ & $108.5 \pm 22.7$ & $13.0 \pm 28.8$ & $150 \pm 180$ \\
\hline $\begin{array}{l}\text { Grand } \\
\text { mean } \pm S D\end{array}$ & $0.5 \pm 1.6$ & $-12.7 \pm 6.3$ & $14.5 \pm 3.5$ & $53.8 \pm 15.6$ & $20.0 \pm 4.0$ & $108.5 \pm 22.7$ & $19.4 \pm 21.3$ & $150.8 \pm 145.1$ \\
\hline
\end{tabular}

$\delta$, Enrichment. 
Table 4. Energy intake and change in body energy stores

\begin{tabular}{|c|c|c|c|c|c|c|}
\hline Subject & $\begin{array}{l}\text { Energy Intake, } \\
\text { mJ/day }\end{array}$ & $\begin{array}{l}\text { Food } \\
\text { Quotient }\end{array}$ & $\begin{array}{l}\text { Change in Body } \\
\text { Weight, kg }\end{array}$ & $\begin{array}{l}\text { Change in Body } \\
\text { Fat, kg }\end{array}$ & $\begin{array}{l}\text { Change in Energy Stores, } \\
\text { MJ/day }\end{array}$ & $\begin{array}{l}\text { Intake-Balance TEE, } \\
\text { MJ/day }\end{array}$ \\
\hline & & & & Test group & & \\
\hline 1 & 6.36 & 0.88 & -0.5 & 0.47 & 1.36 & 5.00 \\
\hline 2 & 6.96 & 0.91 & 1.7 & -0.58 & -1.98 & 8.95 \\
\hline 3 & 7.95 & 0.86 & 1.3 & -0.54 & -1.78 & 9.74 \\
\hline \multirow[t]{2}{*}{4} & 8.53 & 0.88 & -0.3 & -0.24 & -0.55 & 9.08 \\
\hline & & & & Control group & & \\
\hline 5 & 10.02 & 0.91 & 0.4 & 0.05 & 0.01 & 10.02 \\
\hline 6 & 6.11 & 0.85 & -0.7 & -0.16 & -0.19 & 6.31 \\
\hline 7 & 7.83 & 0.89 & -0.8 & -0.31 & -0.55 & 8.39 \\
\hline 8 & 7.40 & 0.86 & -0.4 & -0.08 & -0.07 & 7.49 \\
\hline Mean \pm SD & $7.65 \pm 1.26$ & $0.88 \pm 0.02$ & $0.09 \pm 0.95$ & $-0.17 \pm 0.34$ & $-0.47 \pm 1.06$ & $8.12 \pm 1.75$ \\
\hline
\end{tabular}

Energy intake was determined from weighed-diet records. Food quotient was determined according to Black et al. (1). Change in body fat was determined by using dual-energy X-ray absorptiometry. Change in energy stores assumed energy densities of $39.748 \mathrm{MJ} / \mathrm{kg}$ fat mass and $4.184 \mathrm{MJ} / \mathrm{kg}$ fat-free mass. TEE, total energy expenditure, which equals energy intake minus change in energy stores. 


\section{Energy expenditure.}

The criterion method for assessing energy expenditure was energy intake-balance, where intake was obtained from the controlled inventory of the same prepackaged foods used on the space shuttle. Mean energy consumed during the 2-wk energy-expenditure periods was $7.65 \pm 1.26 \mathrm{MJ} /$ day. Subjects tended to be in negative energy balance during the $2 \mathrm{wk}(-0.47 \pm 1.06 \mathrm{MJ} / \mathrm{day})$, as indicated by small energy losses from body stores (Table 4).

Energy expenditure was calculated from DLW results for the four test subjects (those who had no equilibration period) from their individual (predose) isotopic baselines, from the mass balancepredicted baseline for the group, from the individual baselines estimated from the isotope disappearance kinetics, and from the change in baseline for the control subjects (Table 5). As expected, the use of the individual (predose) measured baselines produced substantial error in the estimate of energy expenditure (Table 5). In contrast, energy-expenditure values from the isotope mass balance predicted baseline underestimated energy expenditure (relative to intake-balance calculations) by only $-0.87 \pm 1.67 \mathrm{MJ} /$ day (not significant). The use of the correction based on the observed changes in baseline in the control group also generated accurate estimates. The use of the baseline predicted from disappearance kinetics was accurate for the test group but was imprecise $(P<0.05$ vs. the isotope balance predicted baseline, $F$-test), as might be expected from the variability in the estimated isotopic abundances at infinite time. 
Table 5. Energy expenditure calculated from energy intake-balance vs. estimates of baseline isotopic abundance

\begin{tabular}{|c|c|c|c|c|c|c|c|c|c|}
\hline Subject & IntakeBalance & $\begin{array}{l}\text { Measured } \\
\text { Baseline }\end{array}$ & & $\begin{array}{l}\text { Predicted } \\
\text { Baseline } \\
\text { (Isotope } \\
\text { Balance) }\end{array}$ & & $\begin{array}{l}\text { Predicted Baseline } \\
\text { (Isotope } \\
\text { Disappearance; Eq. 9) }\end{array}$ & & $\begin{array}{l}\text { Predicted Baseline } \\
\text { (Control } \\
\text { Subjects; Eq.10) }\end{array}$ & \\
\hline & TEE & TEE & Error & TEE & Error & TEE & Error & TEE & Error \\
\hline & & & & & $\begin{array}{l}\text { Test } \\
\text { group }\end{array}$ & & & & \\
\hline 1 & 5.00 & 3.71 & -1.29 & 6.07 & 1.07 & 8.36 & 2.48 & 6.60 & 1.60 \\
\hline 2 & 8.95 & 6.31 & -2.64 & 8.47 & -0.48 & 9.98 & 2.40 & 8.98 & 0.03 \\
\hline 3 & 9.74 & 5.49 & -4.25 & 6.78 & -2.96 & 6.24 & -2.28 & 7.56 & -2.18 \\
\hline 4 & 9.08 & 5.58 & -3.50 & 7.98 & -1.10 & 5.36 & -3.43 & 8.48 & -0.60 \\
\hline $\begin{array}{l}\text { Mean } \pm \\
\text { SD }\end{array}$ & $8.19 \pm 2.16$ & $5.27 \pm 1.10$ & $\begin{array}{l}-2.92 \pm \\
1.275- \\
150\end{array}$ & $7.31 \pm 1.08$ & $\begin{array}{l}-0.87 \\
\pm 1.67\end{array}$ & $7.48 \pm 2.08$ & $\begin{array}{l}-0.71 \pm \\
3.495- \\
151\end{array}$ & $7.91 \pm 1.05$ & $\begin{array}{l}-0.29 \\
\pm 1.56\end{array}$ \\
\hline
\end{tabular}

TEE in MJ/day.

${ }^{\text {F5-150 }} P<0.05$ [intake-balance vs. measured (predose) baseline];

${ }^{55-151} P<0.05$ (variance of baselines predicted from isotope- disappearance kinetics vs. mass balance). 
Energy expenditure also was calculated for the control subjects from their (predose) urine samples, from individual baselines estimated from the isotope-appearance kinetics, from the isotopedisappearance kinetics, and from isotope balance predicted baselines (Table6). Control subjects had 2 wk to partially equilibrate to the enriched water (which corresponds to $\sim 2$ biological half-lives). The energy-expenditure values from DLW were accurate with the use of any of the methods. However, the precision of the elimination predicted baseline was reduced relative to that of the test subjects from the isotope balance predicted baseline $(P<0.01)$. The precision predicted from appearance kinetics tended to be worse than that of the isotope balance predicted baseline; however, the difference did not reach statistical significance $(P>0.05, F$-test). 
Table 6. Energy expenditure calculated for subjects who consumed enriched water for 14 days before DLW dosing

\begin{tabular}{|c|c|c|c|c|c|c|c|c|c|}
\hline Subject & $\begin{array}{l}\text { Intake- } \\
\text { Balance }\end{array}$ & $\begin{array}{l}\text { Measured } \\
\text { Baseline }\end{array}$ & & $\begin{array}{l}\text { Predicted } \\
\text { Baseline } \\
\text { (Isotope } \\
\text { Balance) }\end{array}$ & & $\begin{array}{l}\text { Predicted Baseline } \\
\text { (Isotope Disappearance } \\
\text { Kinetics; Eq. 9) }\end{array}$ & & $\begin{array}{l}\text { Predicted Baseline } \\
\text { (Isotope Appearance } \\
\text { Kinetics; Eq. 10) }\end{array}$ & \\
\hline & TEE & TEE & Error & TEE & Error & TEE & Error & TEE & Error \\
\hline & & & & & & Control group & & & \\
\hline 5 & 10.02 & 9.61 & -0.41 & 9.80 & -0.22 & 9.58 & -0.40 & 9.02 & -1.00 \\
\hline 6 & 6.31 & 7.04 & 0.73 & 7.07 & 0.76 & -8.06 & -14.35 & 7.76 & 1.45 \\
\hline 7 & 8.39 & 8.88 & 0.49 & 8.72 & 0.33 & -0.47 & -8.63 & 6.49 & -1.90 \\
\hline 8 & 7.49 & 10.34 & 2.85 & 8.30 & 0.81 & 37.68 & 30.19 & 11.28 & 3.79 \\
\hline $\begin{array}{l}\text { Mean } \pm \\
\text { SD }\end{array}$ & $\begin{array}{l}8.05 \pm \\
1.57\end{array}$ & $8.92 \pm 1.52$ & $\begin{array}{l}0.92 \pm \\
1.38\end{array}$ & $8.47 \pm 1.13$ & $\begin{array}{l}0.42 \pm \\
0.49\end{array}$ & $9.68 \pm 20.01$ & $\begin{array}{l}1.63 \pm \\
19.886- \\
150\end{array}$ & $8.64 \pm 2.04$ & $\begin{array}{l}0.59 \pm \\
2.56\end{array}$ \\
\hline
\end{tabular}

TEE in MJ/day. DLW, doubly labeled water.

${ }^{\mathrm{F} 6-150} P<0.05$ (variance of isotope disappearance kinetics vs. mass balance). 


\section{DISCUSSION}

This is the first controlled investigation of how a change in isotope abundance affects the accuracy and precision of the DLW method. Previous investigations have involved either observations of background changes in largely uncontrolled situations in natural settings $(4,7)$, clinical situations in which the control was dictated by medical practice $(8,9,16)$, or situations in which only computer simulations were possible $(13,21)$. Moreover, the background changes imposed in this investigation were larger than those encountered under most conditions. This combination of control plus a large change in background provided an excellent opportunity to demonstrate that background changes can negatively affect this method. More importantly, we were able to demonstrate that the deleterious effects could be mitigated by using approaches applied by previous investigators or a new approach that is based on estimates of final equilibrated isotope abundance.

The potential for error under changing background conditions was illustrated clearly by the average error of $2.9 \mathrm{MJ}$ for the four test subjects, when the isotope-disappearance rates were calculated without considering the change in background. Intersubject variability was not inflated and did not provide any indication of problems, because the subjects all showed the same changes in background that could be expected from introducing a new water source.

This 2.9-MJ bias is much larger than that reported by DeLany et al. (4) or Jones et al. (7), who used the DLW method to measure energy expended by soldiers who had been transported to a new location to engage in field exercises. However, subjects in these studies consumed water from natural sources, with isotopic compositions close to the meteoric water line (3). Thus the ratio of change in baseline isotopic abundance was roughly 6:1 ${ }^{2} \mathrm{H}$ /oxygen, which resembles the enrichment of these isotopes in body water after standard doses. Therefore, the errors produced in the rates of disappearance of ${ }^{2} \mathrm{H}$ and oxygen isotopes were covariant and largely canceled each other out in the calculations of energy expenditure, because this calculation depends on the difference between the two elimination rates.

The present study confirms the utility of using an equilibration period when the isotopic enrichment of the water source for subjects is altered. The 2-wk period used in this study was adequate for the calculation despite its being insufficient for full equilibration to the new water source. Indeed, the predose isotopic abundance in the control subjects had reached only $\sim 75 \%$ of the estimated final equilibration. Nonetheless, no bias was detected nor relative precision lost. These results indicated that partial equilibration was sufficient to obviate the problems of the unusual isotopic composition of the enriched water. The isotopic composition of the experimental water source in the present study was chosen to mimic the water that astronauts consume aboard the space shuttles. The bias observed in this study, however, documents the estimates of bias made by Schoeller et al. (16) and Pullicino et al. (11), whose subjects were fed intravenously with water that had an unusual isotopic composition arising from the distillation process (11).

The present study also confirms the validity of using control groups to track changes in isotope backgrounds when full or partial equilibration periods are not feasible. In addition, we have demonstrated that baseline changes can be corrected equally well without a control group but, instead, by calculating the final equilibrated-baseline isotope abundance from isotope mass balance. The coefficient of variation for this correction was $13 \%$, which is similar to that reported by Jones et al. 
(8) but worse than the 7-8\% reported by DeLany et al. (4) using a control group. A $13 \%$ coefficient of variation also characterized the control group in the present study, suggesting that poor precision was due to the isotopic composition of the enriched water rather than to the method itself.

The use of isotope-disappearance kinetics to predict final baselines failed, probably because of the need to extrapolate too far from the final data point, as indicated by model-derived uncertainties in the estimated final isotopic abundances of $21 \%$ o for oxygen and $145 \%$ o for ${ }^{2} \mathrm{H}$. This variability might have been reduced if urine samples had been collected during two additional biological half-lives during the evaluation period.

The advantage of the correction method described in this paper that is based on the final isotope ratio of the fully equilibrated baseline isotope abundance is that it does not require that a subset of subjects be relegated to a control group, an important consideration when the number of subjects is limited. The disadvantage of this method is that it requires the isotopic composition of the various inputs to be relatively constant and that the information be available to calculate isotope balance. Furthermore, because the isotope-balance correction method is sensitive to errors in the estimates of the input functions (17), it does not provide quite as much confidence as would tracking a change in baseline in a control group. Fortunately, most of the 19 factors needed to calculate mass balance (Table 2) are known and should remain relatively constant. Only the isotopic abundance of the new water source and the fractions of elemental influx and efflux are highly variable. The constituents of the new water can be measured readily, and the fractions of elemental influx and efflux can be estimated (14). The prediction will never be perfect, however, because these parameters are subject to physiological variations. In general, these variations will cause the baseline abundance of both isotopes to vary, typically with a $6: 1$ change in the per mill abundance of ${ }^{2} \mathrm{H}$ and oxygen $(3,17)$. Thus it is important to use isotope loading doses that produce 6:1\% enrichments of these isotopes in body water and to limit the metabolic period to less than two biological half-lives $(2,13,18)$.

In summary, we have validated a new correction procedure for the DLW method for situations in which the background abundance of isotopes cannot be kept constant. In addition, we have validated the commonly used control subject correction method, which has been assumed to be valid. The new method has been validated under conditions that simulate space shuttle flight and thus will permit the DLW method to be used to assess human energy expenditure under the unique conditions of space flight.

The authors appreciate the efforts of Christine Wogan of KRUG Life Sciences in clarifying this presentation.

\section{FOOTNOTES}

- This work was supported by the National Aeronautics and Space Administration-Johnson Space Center and by National Institute of Diabetes and Digestive and Kidney Diseases Grant DK26678.

\section{REFERENCES}


1 Black A. E., Prentice A. M., Coward W. A.Use of food quotients to predict respiratory quotients for the doubly labeled water method of measuring energy expenditure.Hum. Nutr. Clin.

Nutr.401986381391

2 Coward A., Cole T.Determination of optimal dosing ratios (Appendix 5).The Doubly Labeled Water Method For Measuring Energy Expenditure: Technical Recommendations for Use in Humans, Prentice A.1990294301Intl. Dietary Energy Consultants Group, Intl. Atomic Energy AgencyVienna, Austria

3 Dansgaard W.Stable isotopes in precipitation.Tellus161964436468

4 DeLany J. P., Schoeller D. A., Hoyt R. W., Askew E. W., Sharp M. A.Field use of $D_{2}{ }^{18} \mathrm{O}$ to measure energy expenditure of soldiers at different energy intakes.J. Appl. Physiol.67198919221929

5 De Weir J. B.New methods for calculating metabolic rate with special reference to protein metabolism.J. Physiol. Lond.109194919

6 Hoyt R. W., Jones T. E., Stein T. P., McAninch G. W., Lieberman H. R., Askew E. W., Cymerman A.Doubly labeled water measurement of human energy expenditure during strenuous exercise.J. Appl. Physiol.7119911622

7 Jones P. J. H., Jacobs I., Morris A., Ducharme M. B.Adequacy of food rations in soldiers during an arctic exercise measured by doubly labeled water.J. Appl. Physiol.75199317901797

8 Jones P. J. H., Winthrop A. L., Schoeller D. A., Filler R. M., Heim T.Evaluation of doubly labeled water for measurement of energy expenditure during changing nutrition.Am. J. Clin. Nutr.471988799804

9 Mitchell I. M., Davies P. S. W., Day J. M. E., Pollock J. C. S., Jamieson M. P. G., Wheatley D. J.Energy expenditure in children with congenital heart disease, before and after cardiac surgery.J. Thorac. Cardiovasc. Surg.1071994374380

10 Prentice A. M., Diaz E. O., Murgatroyd P. R., Goldberg G. R., Sonko B. J., Black A. E., Coward W. A.Doubly labeled water measurements and calorimetry in practice. New Techniques in Nutritional Research, Whitehead R. G.1990AcademicNew Yorkchapt. 8, p. 177-206.

11 Pullicino E., Coward A., Elia M.Total energy expenditure in intravenously fed patients measured by the doubly labeled water method.Metab. Clin. Exp.4219935864

12 Racette S. B., Schoeller D. A., Luke A. H., Shay K., Hnilicka J., Kushner R. F.Relative dilution spaces of ${ }^{2} \mathrm{H}$ - and ${ }^{18} \mathrm{O}$-labeled water in humans.Am. J. Physiol.267Endocrinol. Metab. 301994E585E590

13 Roberts S., Coward W. A., Ewing G., Savage J., Cole T. J., Lucas A.Effect of weaning on accuracy of doubly labeled water method in infants.Am. J. Physiol.254Regulatory Integrative Comp. Physiol. 231988R622R627

14 Schoeller D. A.Changes in isotopic backgroundThe Doubly Labeled Water Method for Measuring Energy Expenditure: Technical Recommendations for Use in Humans, Prentice A.1990Intl. Dietary Energy Consultants Group, Intl. Atomic Energy AgencyVienna, Austriachapt. 8, p. 147165.

15 Schoeller D. A., Coward W. A.Practical consequences of deviations from the isotope elimination model.The Doubly Labeled Water Method For Measuring Energy Expenditure: Technical Recommendations for Use in Humans, Prentice A.1990Intl. Dietary Energy Consultants Group, Intl. Atomic Energy AgencyVienna, Austriachapt. 9, p. 166-192, 1990.

16 Schoeller D. A., Kushner R. F., Jones P. H.Validation of doubly labeled water for measuring energy expenditure during parenteral nutrition.Am. J. Clin. Nutr.441986291298

17 Schoeller D. A., Leitch C. A., Brown C.Doubly labeled water method: in vivo oxygen and hydrogen isotope fractionation.Am. J. Physiol.251Regulatory Integrative Comp. Physiol. 201986R1137R1143 
18 Schoeller D. A., Ravussin E., Schutz Y., Acheson K. J., Baertschi P., Jequier E.Energy expenditure by doubly labeled water: validation in humans and proposed calculation.Am. J.

Physiol.250Regulatory Integrative Comp. Physiol. 191986R823R830

19 Socki R. A., Karlsson H. R., Gibson E. K.Extraction technique for the determination of oxygen-18 in water using preevacuated glass vials.Anal. Chem.641992829831

20 Spector E., LeBlanc A., Shackelford L.Hologic QDR 2000 whole body scans: a comparison of three combinations of scan modes and analysis software.Osteoporosis Int.51995440445

21 Tatner P.Deuterium and oxygen-18 abundance in birds: implications for DLW energetics studies.Am. J. Physiol.258Regulatory Integrative Comp. Physiol. 271990R804R812

22 Zanconato S., Cooper D. M., Armon Y., Epstein S.Effect of increased metabolic rate on oxygen isotope fractionation.Respir. Physiol.891992319327 